Original Article (short paper)

\title{
The relationship between relative age effects and sex, age categories and playing positions in Brazilian National Handball Teams
}

\author{
Lucas Savassi Figueiredo ${ }^{1}$ (1) , Petrus Gantois ${ }^{2}$ (1) , Dalton de Lima-Junior ${ }^{2}$ (1) , Leonardo de Sousa Fortes² (i) , \\ Fabiano de Souza Fonseca ${ }^{3}$ (i) \\ ${ }^{1}$ Universidade Federal de Minas Gerais, Belo Horizonte, $M G$, Brasil; ${ }^{2}$ Universidade Federal da \\ Paraiba, João Pessoa, PB, Brasil; ${ }^{3}$ Universidade Federal Rural de Pernambuco, Recife, PE, Brasil.
}

Associate Editor: Gustavo R da Mota. UFTM/Uberaba, MG, Brazil

\begin{abstract}
Aims: This study investigated the existence of Relative Age Effect (RAE) in the selection process of male and female athletes in the Brazilian national handball teams according to age categories (U-18, U-21, and senior) and playing position (wings, backs, pivots, and goalkeepers). Methods: In order to determine RAE, athletes were divided based on their months of birth; quarters Q1 (JanuaryMarch), Q2 (April-June), Q3 (July-September), and Q4 (October-December). Data were collected from the official Brazilian Handball Confederation $(\mathrm{CBHb})$ website and included the athletes that participated in training and/or competitions composing the Brazilian national teams from 2014 to 2018. To determine the RAE on playing positions, age categories of male and female groups were pooled. Chi-squared tests were performed to investigate the RAE. Results: An over-representation of players born in Q1 and Q2 in the U-18, U-20, and senior categories of male teams and the U-20, and senior female teams were found. In the male teams, as the age category increased, RAE decreased, but still existed. Such distribution was reversed in the female athletes, with a higher RAE magnitude in the senior category as compared to U-18 and U-21. Additionally, it seems that RAE is dependent on the playing position only for male athletes (wings and backs) whereas RAE was found for all playing positions in female athletes. Conclusion: Overall, RAE was found in Brazilian national handball teams, but its magnitude and form of manifestation seem to be influenced by sex, category, and playing position.
\end{abstract}

Keywords: relative age effect; handball; age categories; talent identification; talent development.

\section{Introduction}

In most team sports, young athletes are grouped in different categories according to their years of birth, aiming at equal opportunities in training and competition settings ${ }^{1}$. However, when athletes born in the same year are grouped, chronological age differences play a role in performance. Athletes born earlier in the year are usually benefited in terms of development and experiences within the same age category ${ }^{1,2}$. Thus, older athletes are prone to be given more opportunities in sports than are younger athletes (i.e., playing in higher competitive levels), which may also lead to preferences in the selection process for competitive sports $^{3,4}$. This phenomenon is known as the Relative Age Effect (RAE) and is observed in many sports and contexts ${ }^{1,5,6}$.

Cobley et al. ${ }^{1}$ conducted a broad meta-analysis to analyze the prevalence and magnitude of RAE in sports. Their study included 130,108 athletes from 253 samples and 14 different sports. Overall, the results confirmed the prevalence of RAE in the analyzed sports, in both individual and team sports. Recent studies have also consistently reported the occurrence of RAE, especially in team sports ${ }^{5,7,8}$. For example, an asymmetry in birthdate distribution was shown among young soccer players, in which relatively older players were over-represented in a wide age range ( 7 to 17 years) as compared to relatively younger players ${ }^{8}$. RAE was also found in elite basketball athletes (U-18). Specifically, $67 \%$ of young players participating in a European Championship were born in the first half of the year ${ }^{7}$. In handball, the skewed distribution of birthdates in elite players (U-19) was recently reported, with more athletes being born in the first semester of the year ${ }^{5}$. There is a robust body of evidence in the literature corroborating the aforementioned findings ${ }^{9-12}$.

Although RAE is prevalent across most sports, researchers have also discovered exceptions and, even shown a reversed effect ${ }^{13,14}$ with an over-representation of relatively younger athletes, which is the case in gymnastics ${ }^{15}$, taekwondo ${ }^{16}$ and U-18 and $\mathrm{U}-20$ female pole vault ${ }^{17}$. One possible explanation is that the occurrence and magnitude of RAE seem to be a multifactorial phenomenon. Wattie et al. ${ }^{2}$ proposed a theoretical model based on Newell's framework of interacting constraints on development ${ }^{18}$ to explain RAE in sport. This model is based on three interacting constraints on development: (a) individual; (b) task; and (c) environmental. Individual constraints relate to individual qualities, such as maturational status, sex, and variability between chronological and biological age. Task constraints concern the specificity of the sport demand (i.e., physical demand and body contact), a competitive level (i.e., recreational vs. highly competitive), and playing position. Finally, environmental constraints relate to aspects such as family influences, sport popularity, and 
sport policies. This theoretical model allows us to generate and evaluate specific RAE hypotheses for specific sport contexts.

In this constraints-based model, sex is considered an important individual constraint influencing RAE in sport ${ }^{2}$. Several studies have shown how robust the phenomenon is for competitive male athletes ${ }^{19,20}$. However, when RAEs are investigated in female athletes, results seem limited and controversial $^{20}$. Romann \& Fuchslocher ${ }^{20}$ investigated RAEs in a U-17 Women's World Cup competition and found that female soccer players underwent less competition to earn a position in an elite team, which was associated with the absence of RAEs in several of the countries participating in the competition. On the other hand, studies carried out in specific contexts confirm the prevalence of RAE at almost all competitive levels of female soccer ${ }^{11}$. Findings from a meta-analysis among female athletes have shown that the frequency and magnitude of RAE in female sports seem to be less extensive than in male settings ${ }^{14}$. The prevalence of RAE among female athletes may be especially influenced by environmental constraints, such as the number of athletes competing for selection, the specific sociocultural context, competitive level, and the popularity of the sport ${ }^{2,11,14}$.

Another individual constraint potentially influencing RAE is age categories. Specifically, the magnitude of RAE seems to increase with age from childhood (U-11) to adolescence (U-15 to $\mathrm{U}-18)$ before declining at the senior level $(<\mathrm{U}-19)^{1}$. The influence of maturational processes is the primary explanation for RAE according to age category ${ }^{1,2}$ as physical and fitness characteristics are strongly affected during adolescence ${ }^{21-23}$. Thus, older athletes (e.g. born in the first months of the year) may experience physical and physiological changes from maturation (e.g. rapid increase in height, muscle-mass gain, strength, speed, and power) before their younger peers. Such differences tend to disappear after the pubertal growth spurt. This might be the reason for the lack of an observed RAE in senior categories for some sports ${ }^{13,24}$.

Finally, playing position is a task constraint that may influence the occurrence of RAE. For many team sports in which different functions are performed according to playing positions, it is expected that athletes with a specific set of skills and physical characteristics will be preferred. In several sports, some specific playing positions rely more on the athlete's physical characteristics, such as increased height, as is the case of defensive soccer players ${ }^{25}$, backrowers, and outside backs in rugby ${ }^{26}$, and greater strength and velocity levels of backs and wing players, respectively, in handball ${ }^{5,27}$. These studies mentioned above show how interacting constraints may shape and influence the RAE in sports and elucidate the importance of investigating specific sport contexts ${ }^{2}$.

Several studies have investigated the RAE in handball and demonstrated its prevalence, whose magnitude seems to be influenced by factors such as sex, context, age category, and playing position, among others ${ }^{5,12,27}$. The characteristics associated with task constraints in handball, such as several repeated high-intensity actions and body contacts as well as technical, physical, and physiological demands, allow athletes who score better on physical performance characteristics and show anthropometric advantages to perform better ${ }^{28}$. It has been reported that models for selection and development of young talented handball players place considerable importance on physical/anthropometric aspects, which are strongly influenced by chronological and biological age modulation ${ }^{29}$. Accordingly, RAE manifests in young-age categories (i.e., U-18) and is perpetuated in even more advanced age categories (i.e., U-19, U-21 and senior) $)^{5,27,30}$ despite the tendency to reduce or stabilize its magnitude or even disappear, after adulthood ${ }^{11-13,29,30}$.

Although research investigating RAEs in handball is available, most studies were carried out in European countries ${ }^{27,29,30}$, where handball presents differences from that played in Brazil in terms of the sport's organizational structure, competitive level, and processes of talent selection and development. These environmental constraints might influence the occurrence and magnitude of $\mathrm{RAE}^{2}$. To the best of our knowledge, studies of RAE in Brazilian handball are limited. More research is needed in order to explore how the RAE influences participation, identification, and development in Brazilian handball. Talent development systems in which RAE is prevalent may lead to a large number of potential talents to be overlooked due to the inequalities generated by their dates of birth ${ }^{1}$. Thus, this study has important practical applications, especially regarding institutional policies within the federations and methodological approach applied by coaches throughout the process of training and developing young athletes, reducing $\mathrm{RAE}^{4}$.

Thereby, this study aimed to investigate the prevalence of RAE in Brazilian national handball teams according to sex, age categories and playing position. Based on the constraints-based model $^{2}$ and previous studies, we hypothesized that RAE would be prevalent in both male and female handball squads ${ }^{9}$, with higher magnitude effects reported for males. In contrast, we hypothesized that smaller effects would be observed for females $^{12}$. We also expected that the magnitude of RAE would decrease as age categories increase, in both male and female contexts ${ }^{1}$. Regarding the playing position analysis, we hypothesized an over-representation of relatively older players in the backcourt and wing positions for both sexes. In the backcourt case, this is based on the fact that there are clear advantages for taller and stronger players, whereas, for the wings, faster players have an advantage as they perform essential speed and repeated-sprint actions during the matches ${ }^{5,9}$.

\section{Methods}

\section{Participants}

The study sample consisted of all Brazilian handball players that composed the Brazilian national handball teams from 2014 to $2018(\mathrm{n}=436)$. The inclusion criterion was participating in the Brazilian squad during national team training, friendly matches, and/or official competitions. For male players, data comprised the categories U-18 $(\mathrm{n}=70$, age range $=15-18$ years $), \mathrm{U}-21(\mathrm{n}=48$, age range $=18-21$ years $)$, and senior $(\mathrm{n}=76$, age range $=19-38$ years $)$. For female players, data comprised the categories $\mathrm{U}-18(\mathrm{n}=85$, age range $=16-18$ years $), U-20(n=78$, age range $=18-20$ years $)$, and senior $(n$ $=79$, age range $=19-37$ years $)$. 
Data collection and Procedures

Data were obtained from the Brazilian Handball Confederation (CBHb) Official Website, according to rosters available at www.brasilhandebol.com.br. This information included players' full names, day, month, and year of birth, playing positions, and age category. Data were organized according to sex, categories, and playing positions. The selected athletes' birthdates were classified according to each player's quarter of birth (Q1 = January-March, Q2 = April-June, Q3 = July-September, and Q4 = October-December). Players that composed the squad in more than one category were considered different players for the category analysis (43 male players and 48 female players). For the playing position analysis, players that composed the squad in more than one category were considered only once, on the playing position they played in the highest category achieved.

\section{Data Analysis}

Data were presented in absolute and relative frequencies. A chi-square test $\left(\chi^{2}\right)$ was performed to compare the birthdate distribution of athletes according to sex, age category and specific playing position. For all analyses, the effect size $(\omega)$ of the chi-square tests was calculated ${ }^{1}$. Considering the number of births in each quartile based on Brazilian reports from 1994 to 2001 (Brazilian Ministry of Health), the prevalence of expected observations in each quartile are: $\mathrm{Q} 1=25.7 \%$ for both men and women, Q2 $=26.3 \%$ and $26.4 \%$ for men and women, respectively, Q3 $=24.8 \%$ for both men and women and $\mathrm{Q} 4=23.2 \%$ and $23.1 \%$ for men and women, respectively. Additionally, the Odds Ratio (ORs) and $95 \%$ confidence intervals were calculated for both Q1 versus Q4 (Q1:Q4) and the first and second semesters of the years $\left(1^{\text {st }}\right.$ versus $\left.2^{\text {nd }}\right)$ for male and female players according to age categories and playing position. The analysis was performed in the Statistical Package for the Social Sciences (SPSS), version 20.0 (Chicago, USA). The $\alpha$ level was set to 0.05 .

\section{Results}

Table 1 shows the absolute distribution in quarters of the dates of birth of U-18, U-21, and senior male handball athletes. The observed distribution for all male categories was different from the expected $(p<0.05)$, whereas we found an overrepresentation of athletes born in the first semester. Moreover, the effect size of the RAE and ORs for senior male athletes resulted in lower values than those for $U-18$ and $U-21$ age categories $(\omega=0.41$ vs. 0.63 and 0.63 for senior, $\mathrm{U}-18$, and $\mathrm{U}-21$ respectively; ORs $=4.30$ vs. 10.07 and 6.14 for senior, U-18 and U-21 respectively). For male athletes, when quarters were pooled in the semester $(\mathrm{Q} 1+\mathrm{Q} 2$ vs. Q3+Q4), higher ORs were found.

Table 2 shows the absolute distribution in quarters of the dates of birth of U-18, U-20, and senior female handball athletes. The observed distributions for U-20 and senior categories were different from the expected $(p<0.05)$, whereas, we found an overrepresentation of athletes born in the first semester. Different findings were reported for the U-18 category, where athletes' birth quartiles were more evenly distributed $(p=0.058)$. Moreover, RAE's effect size and ORs for female athletes increased as categories increased $(\omega=$ 0.25 vs. 0.33 and 0.51 for $\mathrm{U} 18, \mathrm{U} 20$ and senior respectively; ORs $=3.38$ vs. 2.77 and 2.55 for senior, $\mathrm{U} 20$ and $\mathrm{U} 18$ respectively). For female athletes, when quarters were pooled in the semester $(\mathrm{Q} 1+\mathrm{Q} 2$ vs. Q3+Q4), higher ORs were found.

Figure 1 shows the distribution in dates of birth quarters of Brazilian male athletes according to their playing positions. The observed distribution was different from the expected for wings $\left(\chi^{2}\right.$ $=19.13 ; \mathrm{p}<0.001 ; \omega=0.62 ;$ OR Q $1: \mathrm{Q} 4=6.97 ;$ OR $1^{\text {st }}: 2^{\text {nd }}=23.90$ ) and back players $\left(\chi^{2}=26.57 ; \mathrm{p}<0.001 ; \omega=0.58\right.$; OR Q1:Q4 $=6.02$; OR $\left.1^{\text {st }}: 2^{\text {nd }}=13.73\right)$. Specifically, an overrepresentation of athletes born in the first semester was found (Q1 and Q2).

Figure 2 shows an overrepresentation of female athletes born in the first and second quarters for all playing positions [wings $\left(\chi^{2}=\right.$ $13.50 ; \mathrm{p}=0.004 ; \omega=0.47 ;$ OR Q1:Q4 $=10.0 ;$ OR $\left.1^{\mathrm{st}}: 2^{\text {nd }}=6.40\right)$; $\operatorname{backs}\left(\chi^{2}=7.67 ; \mathrm{p}=0.050 ; \omega=0.27 ;\right.$ OR Q1:Q4 $=1.67 ;$ OR $1^{\text {st }} 2^{\text {nd }}$ $=3.01)$; pivots $\left(\chi^{2}=9.42 ; \mathrm{p}=0.024 ; \omega=0.47\right.$; OR Q1:Q4 $=1.24$; OR $\left.1^{\text {st }} 2^{\text {nd }}=4.29\right) ;$ and goalkeepers $\left(\chi^{2}=8.23 ; \mathrm{p}=0.041 ; \omega=0.49\right.$; OR Q1:Q4 = 11.20; OR $\left.\left.1^{\text {st: }} 2^{\text {nd }}=7.72\right)\right]$.

Table 1 - Absolute distribution of dates of birth as a function of the tournament category for male handball players.

\begin{tabular}{|c|c|c|c|c|c|c|}
\hline \multirow[b]{2}{*}{$\begin{array}{l}\text { Quarter of date } \\
\text { of birth }\end{array}$} & \multicolumn{2}{|c|}{ U-18 } & \multicolumn{2}{|c|}{ U-21 } & \multicolumn{2}{|c|}{ SENIOR } \\
\hline & Observed & Expected & Observed & Expected & Observed & Expected \\
\hline Q1 & $34^{\mathrm{c}, \mathrm{d}}$ & 18.0 & $20^{\mathrm{c}, \mathrm{d}}$ & 12.3 & $32^{\mathrm{c}, \mathrm{d}}$ & 19.5 \\
\hline Q2 & $23^{\mathrm{c}, \mathrm{d}}$ & 18.4 & $20^{\mathrm{c}, \mathrm{d}}$ & 12.6 & 21 & 20.0 \\
\hline Q3 & 07 & 17.4 & 03 & 11.9 & 12 & 18.8 \\
\hline Q4 & 06 & 16.2 & 05 & 11.1 & 11 & 17.6 \\
\hline$\chi^{2}$ & \multicolumn{2}{|c|}{28.03} & \multicolumn{2}{|c|}{19.11} & \multicolumn{2}{|c|}{12.99} \\
\hline$p$ value & \multicolumn{2}{|c|}{$<0.001$} & \multicolumn{2}{|c|}{$<0.001$} & \multicolumn{2}{|c|}{0.05} \\
\hline$\omega$ & \multicolumn{2}{|c|}{0.63} & \multicolumn{2}{|c|}{0.63} & \multicolumn{2}{|c|}{0.41} \\
\hline $\begin{array}{l}\text { OR (Q1:Q4) } \\
\text { IC95\% }\end{array}$ & \multicolumn{2}{|c|}{$\begin{array}{c}10.07 \\
\text { (6.89 to } 14.70)\end{array}$} & \multicolumn{2}{|c|}{$\begin{array}{c}6.14 \\
\text { (3.76 to } 10.01)\end{array}$} & \multicolumn{2}{|c|}{$\begin{array}{c}4.30 \\
\text { (2.17 to } 8.47)\end{array}$} \\
\hline $\begin{array}{c}\text { OR }\left(1^{\text {st }} 2^{\text {nd }}\right) \\
\text { IC } 95 \%\end{array}$ & \multicolumn{2}{|c|}{$\begin{array}{c}25.00 \\
\text { (20.78 to } 30.06)\end{array}$} & \multicolumn{2}{|c|}{$\begin{array}{c}19.22 \\
\text { (14.33 to } 25.77)\end{array}$} & \multicolumn{2}{|c|}{$\begin{array}{c}5.31 \\
(4.70 \text { to } 5.99)\end{array}$} \\
\hline
\end{tabular}

Q1-Q4 = birth quarter; $\chi^{2}=$ Chi-square value; $\omega=$ effect size; OR = odds ratio; $Q 1: Q 4=$ first quarter compared to fourth quarter; $1^{\text {st }}: 2^{\text {nd }}=$ first semester compared to second semester. $\mathrm{c}$ and $\mathrm{d}=$ pairwise Chi-square comparison different from Q3 and Q4, respectively (adjusted for multiple comparison). 
Table 2 - Absolute distribution of dates of birth as a function of the tournament category for female handball players.

\begin{tabular}{|c|c|c|c|c|c|c|}
\hline \multirow[b]{2}{*}{ Quarter of date of birth } & \multicolumn{2}{|c|}{ U-18 } & \multicolumn{2}{|c|}{ U-20 } & \multicolumn{2}{|c|}{ SENIOR } \\
\hline & Observed & Expected & Observed & Expected & Observed & Expected \\
\hline Q1 & 30 & 21.8 & 24 & 20.0 & 26 & 20.3 \\
\hline Q2 & 24 & 22.4 & $29^{\mathrm{d}}$ & 20.6 & $31^{\mathrm{c}, \mathrm{d}}$ & 20.9 \\
\hline Q3 & 16 & 21.1 & 14 & 19.3 & 12 & 19.6 \\
\hline Q4 & 15 & 19.6 & 11 & 18.0 & 10 & 18.2 \\
\hline$\chi^{2}$ & \multicolumn{2}{|c|}{5.47} & \multicolumn{2}{|c|}{8.42} & \multicolumn{2}{|c|}{13.20} \\
\hline$p$ value & \multicolumn{2}{|c|}{0.140} & \multicolumn{2}{|c|}{0.038} & \multicolumn{2}{|c|}{0.004} \\
\hline$\omega$ & \multicolumn{2}{|c|}{0.25} & \multicolumn{2}{|c|}{0.33} & \multicolumn{2}{|c|}{0.51} \\
\hline $\begin{array}{l}\text { OR (Q1:Q4) } \\
\text { IC95\% }\end{array}$ & \multicolumn{2}{|c|}{$\begin{array}{c}2.55 \\
(.95 \text { to } 6.84)\end{array}$} & \multicolumn{2}{|c|}{$\begin{array}{c}2.71 \\
\text { (2.42 to } 3.02)\end{array}$} & \multicolumn{2}{|c|}{$\begin{array}{c}3.38 \\
\text { (2.98 to } 3.82 \text { ) }\end{array}$} \\
\hline $\begin{array}{l}\text { OR }\left(1^{\text {st: }} 2^{\text {nd }}\right) \\
\text { IC } 55 \%\end{array}$ & \multicolumn{2}{|c|}{$\begin{array}{c}3.03 \\
(1.12 \text { to } 3.13)\end{array}$} & \multicolumn{2}{|c|}{$\begin{array}{c}4.49 \\
\text { (3.99 to } 4.99 \text { ) }\end{array}$} & \multicolumn{2}{|c|}{$\begin{array}{c}6.71 \\
\text { (5.90 to } 7.58)\end{array}$} \\
\hline
\end{tabular}

Q1-Q4 = birth quarter; $\chi^{2}=$ Chi-square value; $\omega=$ effect size; $O R=$ odds ratio; Q1:Q4 = first quarter compared to fourth quarter; $1^{\text {st }}: 2^{\text {nd }}=$ first semester compared to second semester. $\mathrm{c}$ and $\mathrm{d}$ = pairwise Chi-square comparison different from Q3 and Q4, respectively (adjusted for multiple comparison).
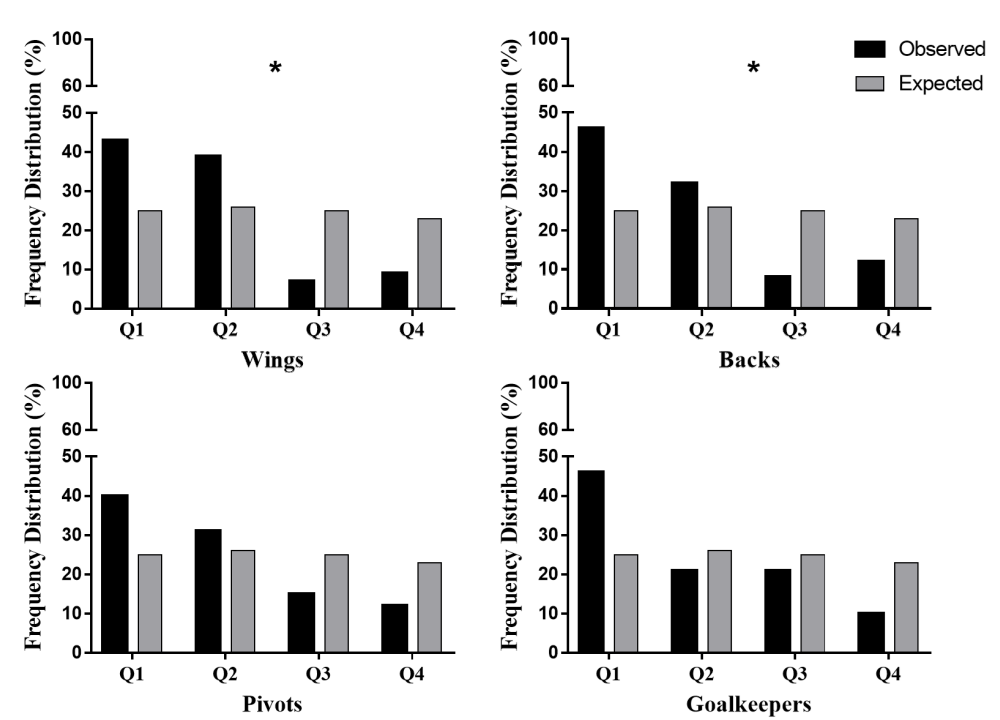

Figure 1 - Distribution of quarters of birth according to the playing position of the Brazilian team's handball male athletes. *= statistical difference between the observed and expected distribution $(\mathrm{p}<0.05)$.
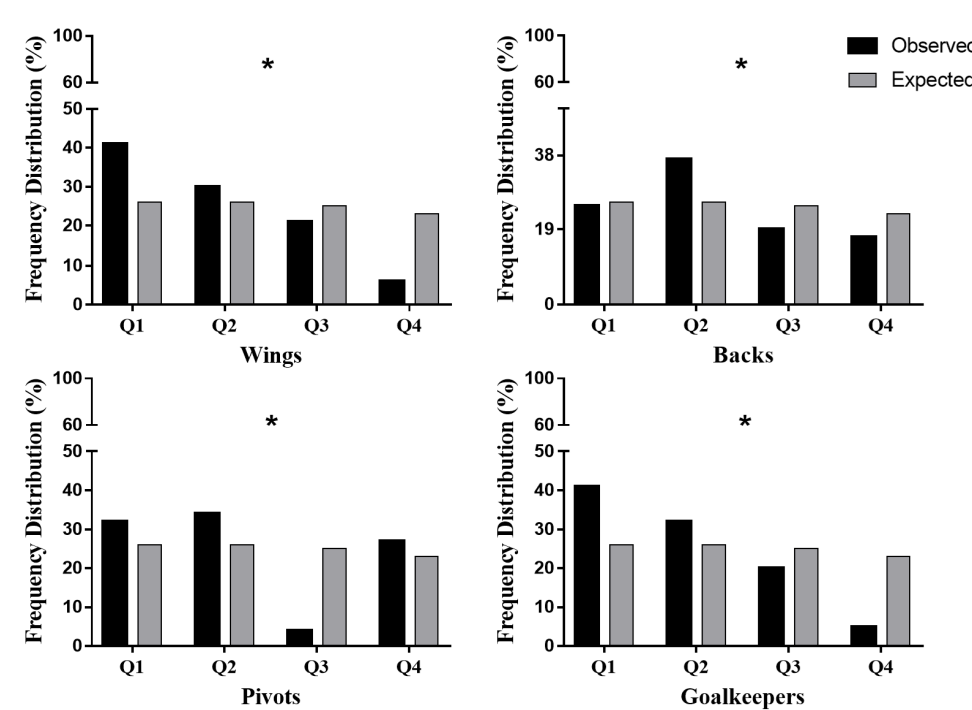

Figure 2 - Distribution of quarters of birth according to the playing position of the Brazilian team's handball female athletes. *= statistical difference between the observed and expected distribution $(\mathrm{p}<0.05)$. 


\section{Discussion}

The present study aimed to analyze the RAE in the Brazilian national handball teams according to sex, age categories, and playing positions. Athletes born in the first quarters of the year were overrepresented in all age categories for both male and female athletes, except for the U-18 female category. Moreover, differences in playing positions were sex-dependent. While RAEs were found for wings and backs in male athletes, this phenomenon was observed for all playing positions in female athletes. Thereby, our hypotheses were partially confirmed. Our findings are in line with those in most studies investigating talent selection mechanisms in team sports ${ }^{1,5,11}$ and suggest that sex, age, and playing position influence RAE prevalence in the Brazilian handball context.

Regarding the sex analysis, higher-magnitude RAEs were found in male categories as compared to their respective female categories in U-18 $(\omega=0.63$ vs 0.25$)$ and $\mathrm{U}-21 / \mathrm{U}-20(\omega=0.63$ vs 0.33 ), but a smaller effect size was observed for the male senior category ( $\omega=0.41 \mathrm{vs} 0.51$ ) as compared to the female senior category. The findings in Brazilian national youth teams are similar to those reported in previous studies that suggest an overall smaller influence of RAE on female athletes ${ }^{1,12,14}$. Environmental constraints may play an important role in understanding the overall smaller magnitude of RAE as compared to those in male national teams. It has been previously proposed that the number of athletes practicing a sport may affect RAE occurrence $^{2}$. This smaller magnitude in the female context could be explained by the "depth of competition" hypothesis, which proposes a higher probability and magnitude of RAE when a large number of athletes are competing for a small number of playing opportunities ${ }^{4,12}$. Official data provided by the Brazilian Handball Confederation currently indicate 33,717 athletes playing in the three age categories investigated in our study. Only $38.3 \%$ of such athletes were females, thus indicating a lower rate of competition for the national squad spots among female athletes. As for the result observed in the senior category, where the female national teams in the present study showed an unexpected high-magnitude RAE, we speculate that environmental constraints other than the "depth of competition" may have more determinant roles. Factors such as the higher levels of sport development in the female senior category, specific talent selection models used by coaches and popularity among the female adult public ${ }^{32}$ may also have influenced the results, although these hypotheses are speculative, since our data do not allow us to reach this conclusion. Besides, these results should be interpreted carefully, as our sample was composed of athletes that participated in the senior national teams over a period of five years, thus reflecting a phenomenon that may be of a transient nature.

Another aim of the study was to investigate the magnitude of RAE as age categories increased, in both male and female Brazilian national teams. In male categories, a larger effect was found for the U-18 and U-21 categories as compared to that for the senior national team. These findings are similar to those found in other studies investigating competitive handball athletes, and they support the hypothesis that RAE is more prevalent in lower-age categories and decreases as the categories increase ${ }^{12,29}$. In high-contact sports, where physical size and strength are decisive for success, significant RAE could exist, especially in the earlier stages of sports participation (e.g. pre-adolescence and adolescence) $)^{2}$. One of the primary explanations for RAE in sports is the role of biological maturation (i.e., maturation-selection hypothesis) ${ }^{1}$. The biological maturation of individuals affects their muscular strength, power, body composition, and endurance performance ${ }^{33,34}$. As handball performance favors athletes with better-developed physical characteristics ${ }^{34,35}$, it is more likely that relatively older youth-level athletes who embody those characteristics earlier will present advantages when compared to their younger peers ${ }^{2,36}$. However, at the adult level, maturational advantages are scarce, since the growth process is supposedly finished ${ }^{37}$. It has been reported that late-maturing athletes may present an increased progression in anthropometric and physical attributes and "catch-up" with the early-maturing athletes during late adolescence and in adulthood ${ }^{33}$. Thus, the latter may increase their potential when they are young adults and are likely to overcome their physical disadvantage during the early selection stage by developing superior technical, tactical, and psychological skills ${ }^{26,33}$. Accordingly, previous research suggests that this advantage may decrease in senior categories ${ }^{37}$. This phenomenon is called "the reversal of advantage" or "the underdog effect" ${ }^{\prime 37,38}$, and it was observed among male athletes in our study.

In the case of females, an opposite tendency was found, since no RAE was identified in the U-18 category, and the magnitudes of RAE increased as categories progressed. Thus, we speculate that found in the female U-18 category, we propose that the female players selected had finished or were at the very end of their puberty ${ }^{37}$. The presence of RAE in the U-20 and senior categories and its greater magnitude in the senior category are surprising findings that are difficult to explain based on the data that we have available in this study. Our findings may indicate a possible paradigm shift in the model for selecting young talents in Brazilian women's handball. Considering the wide age range of the female senior sample (16-37 years) and the large proportion (56\%) of athletes over 26.5 years old (half of the age range), our data may comprise at least two generations of athletes (a younger and an older generation). These different generations may have gone through different talent-selection models. The absence of RAE in U-18 and its small magnitude observed in U-20 may suggest that the selection of talents in the younger generations does not seem to be based on factors that increase the likelihood of a high RAE prevalence ${ }^{14,39}$. On the other hand, the greater magnitude of RAE found in the senior category suggests the opposite. We emphasize that, in order to confirm these speculations, longitudinal investigations with the next generations of female athletes from the Brazilian national teams will be necessary.

The playing-position analysis showed RAE for back and wing players in male athletes, as hypothesized. On the other hand, the analysis of female athletes showed the prevalence of RAE in all playing positions. This finding is somehow surprising since previous studies had shown that the specific demands and functions performed in the game seem to determine the presence of RAE only for wing and back players ${ }^{5,12}$. This is because, 
in handball, some playing positions are believed to be more physically demanding than others ${ }^{12,28}$. Specifically, back athletes tend to participate in the central defense field aiming to block the opponents' shots, perform several shooting actions (e.g., distant shots and over the defensive block) and high-intensity movements that require increased body size $\mathrm{e}^{28,40}$. These demands may explain the selective preference for relatively older back athletes in earlier developmental stages. In those relatively older athletes, early maturation could lead to greater heights, levels of strength, and speed than those of their younger peers in the selection process $^{36,41}$.

Conversely, wing players are generally the smallest in the team ${ }^{35,40}$. They play in the outer aisles of the playing field in both the attack and defense phases ${ }^{35}$. In these areas, $6 \mathrm{~m}$ shots are more commonly performed than are the $9 \mathrm{~m}$ ones. Thus, wing athletes do not often shoot over blocks and, consequently, height is not determinant for them ${ }^{40}$. Although wing athletes have low stature, they are more involved with speed and repeated-sprint actions and perform most of the counterattack during the match ${ }^{28}$. Previous studies reported that relatively older athletes overcome their younger peers in the sprint, vertical jump, and repeated-sprint performance ${ }^{34,36}$. Considering that these attributes discriminate against the selected vs. non-selected, skillful vs. less skillful and competitive levels of athletes in several team sports ${ }^{10,36}$, it is not surprising that relatively older athletes have an advantage during selection processes in wing and back positions. These results may support the interaction between task constraints ${ }^{2}$ (i.e., specific sports demands) to explain the observed RAE in the Brazilian national male handball teams. It is also relevant to point out that, although no significant differences were found in male goalkeepers and pivots $(p>0.05)$, an overrepresentation of athletes born in the first quartile for these positions is noticeable. Possibly, RAEs were not statistically detected due to the small sample size, which influences the results of the chi-square tests.

In females, unlike in males, the RAE was found in the analyses of all playing positions. Although RAEs are expected in more physically demanding positions ${ }^{12,26}$, such as wings and back players $^{5,12}$, it does not mean that such effect would be unexpected in other playing positions, especially in high-level competition, as is the case of national teams. Pivot and goalkeeper positions also have specific physical and anthropometric requirements that may pose as advantageous for relatively younger players, such as coordination capacity for goalkeepers and higher strength levels for pivots ${ }^{28}$. With this regard, task constraints ${ }^{2}$ seem to play an important role, influencing the magnitude of RAEs in female Brazilian national handball teams, especially when playing positions are taken into account.

As a whole, our results indicate the prevalence of RAE in Brazilian national handball teams, which corroborates previous studies that also found RAE in handball athletes worldwide ${ }^{5,12,34}$. Since the date of birth is a key factor to reach Brazilian national handball teams, one could argue that this is an indication of coaches' pursuit of early performance. As relatively older athletes are often perceived as more talented, athletes showing advanced maturation are more likely to be selected ${ }^{42}$. This logic creates inequalities in selection, training, and competition contexts, reducing the possibilities of relatively younger athletes to reach professional level ${ }^{1}$. This may be a critical factor in the development of Brazilian handball since detecting and selecting talents should be based on a multi-dimensional perspective that avoids talent loss, especially because athletes who stand out in younger categories will not necessarily maintain their performance advantage as they progress to older age categories ${ }^{42,43}$.

In order to minimize possible inequalities generated by the RAE in Brazilian national handball teams, we will present some counter-RAE interventions below. One of the simplest ways to deal with RAE in selection-based sports systems would be for sports organizations to invest more money in athletes' development at the grass-roots level, instead of selecting international teams at the youth levels, thus delaying talent-selection processes ${ }^{1}$. Assuming that this proposal may not apply to all sports settings, due to budgetary and structural restrictions, other possible solutions are also provided. It has been suggested that the age-group cohort in children and youth's competitions should be reduced and that these competitions should have rules that force teams to have at least $40 \%$ of their players born in the second semester of the year ${ }^{44}$. Another way to reduce RAEs would be to elucidate the differences caused by chronological age during the selection process, which could be achieved by employing age-ordered shirt numbering according to birth distribution, helping coaches evaluate through the awareness of the athlete's age ${ }^{45}$. Finally, coaches and managers responsible for the Brazilian handball organization must be oriented towards the effects of relative age and its consequences so that preventive strategies can be applied in the Brazilian handball processes of talent development and selection.

\section{Conclusions}

In summary, this study confirmed the prevalence of the RAE in most categories of Brazilian national handball teams, with an overrepresentation of athletes born in the first two quarters of the year. This implies that potentially talented athletes might be systematically overlooked, which could be avoided by the implementation of counter-RAE interventions. Moreover, our data indicate that the RAE emerges as a complex phenomenon in the context of the Brazilian national handball teams and that its magnitude and form of manifestation seem to be influenced by sex, category, and playing position. Specifically in the analysis of female athletes, novel and unexpected findings were found, which calls for future studies with a longitudinal approach. A comprehensive understanding of RAE in Brazilian female handball may facilitate the implementation of context-specific policies to minimize long-term inequalities related to the effect of relative age.

\section{References}

1. Cobley S, Baker J, Wattie N, McKenna J. Annual age-grouping and athlete development: A meta-analytical review of relative age effects in sport. Sports Med. 2009;39(3):235-256. 10.2165/00007256-200939030-00005 
2. Wattie N, Schorer J, Baker J. The relative age effect in sport: a developmental systems model. Sports Med. 2015;45(1):83-94. 10.1007/s40279-014-0248-9

3. Müller L, Gehmaier J, Gonaus C, Raschner C, Müller E. Maturity status strongly influences the relative age effect in international elite under-9 soccer. J Sports Sci Med. 2018;17(2):216-222.

4. Musch J, Grondin S. Unequal competition as an impediment to personal development: A review of the relative age effect in sport. Dev Rev. 2001;21(2):147-167. 10.1006/drev.2000.0516

5. Fonseca FS, Figueiredo LS, Gantois P, Lima-Junior D, Fortes LS. Relative age effect is modulated by playing position but is not related to competitive sucess in elite under-19 handball athletes. Sports. 2019;7(4):1-10. 10.3390/sports7040091

6. Campos F, Stanganelli LC, Rabelo F, Campos LC, Pellegrinotti I. The relative age effect in male volleyball championships. Int J Sports Sci. 2016;6(3):116-120. 10.5923/j.sports.20160603.08

7. Ibanez SJ, Mazo A, Nascimento J, Garcia-Rubio J. The Relative Age Effect in under-18 basketball: Effects on performance according to playing position. PloS one. 2018;13(7). 10.1371/ journal.pone.0200408

8. Jackson RC, Comber G. Hill on a mountaintop: A longitudinal and cross-sectional analysis of the relative age effect in competitive youth football. J Sports Sci. 2020; jan (9); 1-7. 10.1080/02640414.2019.1706830

9. Brustio PR, Lupo C, Ungureanu AN, Frati R, Rainoldi A, Boccia $\mathrm{G}$. The relative age effect is larger in Italian soccer top-level youth categories and smaller in Serie A. PloS One. 2018;13(4):1-12. 10.1371/journal.pone.0196253

10. Torres-Unda J, Zarrazquin I, Gravina L, Zubero J, Seco J, Gil $\mathrm{SM}$, et al. Basketball performance is related to maturity and relative age in elite adolescent players. J Strength Cond Res. 2016;30(5):1325-1332. 10.1519/jsc.0000000000001224

11. Sedano S, Vaeyens R, Redondo JC. The relative age effect in Spanish female soccer players. Influence of the competitive level and a playing position. J Hum Kinet. 2015;46(1):129-137. 10.1515/hukin-2015-0041

12. Schorer J, Cobley S, Büsch D, Bräutigam H, Baker J. Influences of competition level, gender, player nationality, career stage and playing position on relative age effects. Scand J Med Sci Sports. 2009;19(5):720-730. 10.1111/j.1600-0838.2008.00838.x

13. Delorme N, Boiché J, Raspaud M. The relative age effect in elite sport: the French case. Res Q Exerc Sport. 2009;80(2):336-344. 10.1080/02701367.2009.10599568

14. Smith KL, Weir PL, Till K, Romann N, Cobley S. Relative Age Effects across and within female sport contexts: a systematic review and meta-analysis. Sports Med. 2018;48; 1451-1478. 10.1007/s40279-018-0915-3

15. Hancock DJ, Starkes DL, Ste-Marie DM. The relative age effect in female gymnastics: A flip-flop phenomenon. Int J Sport Psychol. 2015;46:714-725. 10.7352/IJSP.2015.46.714

16. Albuquerque MR, Lage GM, da Costa VT, Ferreira RM, Penna EM, Moraes LCCA, et al. Relative age effect in Olympic Taekwondo athletes. Percept Mot Skills. 2012;114(2):461-468. 10.2466/05.25.PMS.114.2.461-468

17. Brustio PR, Kearney PE, Lupo C, Ungureanu AN, Mulasso A, Rainoldi A, et al. Relative Age influences performance of world-class track and field athletes even in the adulthood.
Front Psychol. 2019;10:1395. Published 2019 Jun 18. 10.3389/ fpsyg.2019.01395

18. Newell KM. Constraints on the development of coordination. In: Wade MG, Whiting HTA, editors. Motor development in children: aspects of coordination and control. Amsterdam: Martin Nijhoff; 1986. p. 341-61.

19. Helsen WF, Van Winckel J, Williams AM. The relative age effect in youth soccer across Europe. J Sports Sci. 2005;23(6):629-636. $10.1080 / 02640410400021310$

20. Romann M, Fuchslocher J. Influences of player nationality, playing position, and height on relative age effects at women's under-17 FIFA World Cup. J Sports Sci. 2013a;31(1):32-40. 10.1080/02640414.2012.718442

21. Malina RM. Physical growth and biological maturation of young athletes. Exerc Sport Sci Rev. 1994;22(1):280-4.

22. Malina RM, Eisenmann JC, Cumming SP, Ribeiro B, Aroso J. Maturity-associated variation in the growth and functional capacities of youth football (soccer) players 13-15 years. Eur J Applied Physiol. 2004;91(5-6):555-562. 10.1007/s00421-003-0995-Z.

23. Sherar LB, Baxter-Jones ADG, Faulkner RA, Russel KW. Does physical maturity and birth date predict talent in male youth ice hockey players? J Sports Sci. 2007;25:879-86. $10.1080 / 02640410600908001$

24. Nakata, H, Sakamoto K. (2011). Relative age effect in japanese male athletes. Percept Mot Skills. 2011;113(2):570-574. 10.2466/05.10.11.PMS.113.5.570-574

25. Romann M, Fuchslocher J. Relative age effects in Swiss junior soccer and their relationship with playing position. Eur J Sport Sci. 2013;13(4):356-363. 10.1080/17461391.2011.635699

26. Till K, Cobley S, Wattie N, O'Hara J, Cooke C, Chapman C. The prevalence, influential factors and mechanisms of Relative Age Effects in UK Rugby League. Scand J Med Sci Sports. 2010;20(2):320-9. 10.1017/CBO9781107415324.004

27. Rubia A, Bjørndal CT, Sánchez-Molina J, Yagüe JM, Calvo JL, Maroto-Izquierdo S. The relationship between the relative age effect and performance among athletes in World Handball Championships. PloS One. 2020;15(3):e0230133. doi:10.1371/ journal.pone.0230133

28. Karcher C., Buchheit M. On-court demands of elite handball, with special reference to playing positions. Sports Med. 2014;44(6):797-814. 10.1007/s40279-014-0164-z

29. Bjørndal CT, Luteberget LS, Till K, Holm S. The relative age effect in selection to international team matches in Norwegian handball. PloS One. 2018;13(12). 10.1371/journal.pone.0209288

30. Wrang CM, Rossing NN, Diernæs RM, Hansen CG, DalgaardHansen C, Karbing DS. Relative Age Effect and the Re-Selection of Danish Male Handball Players for National Teams. J Hum Kinet. 2018;63:33-41. 10.2478/hukin-2018-0004

31. Matthys SPJ, Fransen J, Vaeyens R, Lenoir M, Philippaerts R. Differences in biological maturation, anthropometry and physical performance between playing positions in youth team handball. J Sports Sci. 2013;31(12):1344-1352. 10.1080/02640414.2013.781663

32. de Souza Andres S, Goellner, SV. Trajetórias esportivas de jogadoras de handebol e suas narrativas sobre ser profissional da modalidade. Movimento. 2018;24(2):527-538. $10.22456 / 1982-8918.79795$ 
33. Malina RM, Rogol AD, Cumming SP, Coelho e Silva MJ, Figueiredo AJ. Biological maturation of youth athletes: Assessment and implications. Br J Sports Med. 2015;49(13):8529, 10.1136/bjsports-2015-094623

34. Matthys S, Vaeyens R, Coelho e Silva MJ, Lenoir M, Philippaerts R. The contribution of growth and maturation in the functional capacity and skill performance of male adolescent handball players. Int J Sports Med. 2012;33(7):543-9. 10.1055/s-0031-1298000

35. Nikolaidis PT, Ingebrigtsen J, Póvoas SC, Moss S, TorresLuque G. Physical and physiological characteristics in male team handball players by playing position - Does age matter? J Sports Med Phys Fitness. 2015;55(4):297-304.

36. Torres-Unda J, Zarrazquin I, Gil J, Ruiz F, Irazusta A, Kortajarena M, et al. Anthropometric, physiological and maturational characteristics in selected elite and non-elite male adolescent basketball players. J Sports Sci. 2013;31(2):196-203. 10.1080/02640414.2012.725133

37. Gibbs BG, Jarvis JA, Dufur MJ. The rise of the underdog? The relative age effect reversal among Canadian-born NHL hockey players: A reply to Nolan and Howell. Int Rev Sociol Sport. 2012;47(5):644-9. 10.1177/1012690211414343

38. McCarthy N, Collins D, Court D. Start hard, finish better: further evidence for the reversal of the RAE advantage. J Sports Sci. 2016;34(15):1461-1465. 10.1080/02640414.2015.1119297

39. Andronikos G, Elumaro AI, Westbury T, Martindale RJ. Relative age effect: implications for effective practice. J Sports Sci. 2016:34(12):1124-1131. 10.1080/02640414.2015.1093647

40. Zapartidis I, Kororos P, Christodoulidis T, Skoufas D, Bayios I. Profile of young handball players by playing position and determinants of ball throwing velocity. J Hum Kinet. 2011;27:17-30. 10.2478/v10078-011-0002-4

41. Till K, Cobley S, O' Hara J, Cooke C, Chapman C. Considering maturation status and relative age in the longitudinal evaluation of junior rugby league players. Scand J Med Sci Sports. 2014;24(3):569-576. 10.1111/sms.12033

42. Johnston K, Wattie N, Schorer J, Baker J. Talent Identification in Sport: A Systematic Review. Sports Med. 2018;48(1):97-109. 10.1007/s40279-017-0803-2

43. Abbott A, Collins D. Eliminating the dichotomy between theory and practice in talent identification and development: considering the role of psychology. J Sports Sci. 2004;22(5):395-408. 10.1080/02640410410001675324

44. Rađa A, Padulo J, Jelaska I, Ardigò LP, Fumarco L. Relative age effect and second-tiers: No second chance for later-born players. PloS One. 2018;13(8):e0201795. 10.1371/journal.pone.0201795

45. Mann DL, Van Ginneken PJMA. Age-ordered shirt numbering reduces the selection bias associated with the relative age effect. J Sports Sci. 2017;35(8):784-790. 10.1080/02640414.2016.1189588

\section{Corresponding author}

Lucas Savassi Figueiredo

Federal University of Minas Gerais, Av. Presidente Carlos Luz, 6627, 31270-901 Belo Horizonte/MG. Brasil.

Email: savassi88@hotmail.com

Manuscript received on March 26, 2020

Manuscript accepted on August 20, 2020

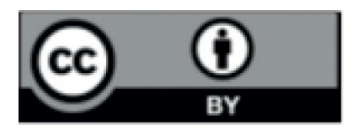

Motriz. The Journal of Physical Education. UNESP. Rio Claro, SP, Brazil - eISSN: 1980-6574 - under a license Creative Commons - Version 4.0 